\title{
A GIG ECONOMY NO CURSO DA CRISE SANITÁRIA: AS RELAÇÕES DE TRABALHO NO CONTEXTO DAS PLATAFORMAS DIGITAIS
}

\section{Ailene de Oliveira Figueiredo* Lourival José de Oliveira*}

\section{RESUMO}

$\mathrm{O}$ artigo tem como objetivo relacionar direito e economia e o emprego das ferramentas de tecnologias de acordo com o valor social do trabalho. Discutiu-se o papel do valor do trabalho no meio ambiente de trabalho tecnológico de execução, relacionando finalidade de custos de transação e lucro, e eficiência jurídica. Concluiu-se que a economia por meio das tecnologias disruptivas de trabalho humano, descumprem o vetor constitucional insculpido no artigo 170 da Constituição Federal. O trabalho foi realizado utilizando o método empírico-dialético, por meio de ferramentas de pesquisa bibliográfica utilizando-se do sistema de referência o Law and Economics por dados secundários.

Palavras-chaves: desenvolvimento; análise econômica do Direito (AED); gig economy; valor-trabalho; tecnologia.

\section{THE GIG ECONOMY IN THE DURING OF THE HEALTH CRISIS: WORKING RELATIONSHIPS IN THE CONTEXT OF DIGITAL PLATFORMS}

\begin{abstract}
The article aims to relate law and economy and the use of technology tools according to the social value of work. Discuss the role of the value of work in the means of technological execution work, relating the purpose of transaction costs and profit and legal efficiency. It was concluded that the economy through disruptive technologies of human labor, does not comply with the constitutional vector incarnated in Article 170 of the Federal Constitution. The work was carried out using the empirical-dialectic method, through bibliographic research tools using the reference system the Law and Economics secondary data.
\end{abstract}

Keywords: development; economic analysis of law; gig economy; value-work; technology.

\section{INTRODUÇÃO}

Grande parte dos estudos sobre a mercantilização da forma de trabalho, em especial no contexto da chamada indústria 4.0, apresentam-na como sinônimo de modernidade ou de processo de modernização, sem uma análise mais aprofundada sobre os resultados obtidos em termos de preservação dos valores sociais nesses novos processos produtivos.

As vertentes analíticas entre Direito e Economia (D\&E), por vezes ignoram entre si os objetos de investigações que lhes são coincidentes. A ciência num primeiro momento se 
desenvolve de forma fragmentada, e para o avanço científico, há a necessidade de conectar os conhecimentos.

A visão interdisciplinar entre direito e economia, se revela como o empírico dotado de um cunho social, essencial para o conteúdo do meio ambiente do trabalho em contexto de análise macroeconômica. É meio necessário de identificação de conteúdo que proporcionem novas abordagens, para que juristas e economistas venham a transpor obstáculos que reconhecidamente se situam entre as duas disciplinas.

Dentro desse contexto, o valor social trabalho é definido como um dos elementos fundantes da economia na composição das relações sociais, a ponto do artigo 170 da Constituição Federal estabelecer que a ordem econômica tem como objetivo ou primado a própria valorização do trabalho.

O trabalho como fundante econômico perfaz o circuito econômico, transita desde as unidades familiares até os conglomerados empresariais, onde constitucionalmente o lucro se acha sobreposto pela produção dos mais variados resultados sociais, dentre os quais destacando-se a redução da desigualdade social.

É importante citar que dentro desse mesmo contexto, tem-se a possiblidade de superação do "modelo clássico" desenvolvimentista sob o ponto de vista estritamente econômico, passando para uma proposta de tentativa de solução dos problemas sociais, ainda que diante de novos procedimentos, que a princípio revelam a finalidade de redução dos custos na produção. Isso significa deixar a vertente baseada puramente no lucro, transpondose para um outro posicionamento que apresenta outras finalidades necessárias de serem alcançadas pela atividade econômica, que se traduzem em requisitos para a própria legitimidade da atividade econômica.

A natureza economicista atribuída às relações de trabalho se estabelecem falsamente nos opostos, numa visão ultrapassada que também contribuiu para o surgimento dos conflitos nas relações de trabalho, baseados na disputa entre capital e trabalho. Observa-se que a mudança da equação aqui apresentada somente poderá ocorrer na medida que de forma efetiva o trabalho produza valores sociais.

Tal perspectiva se torna mais desafiadora em tempos de crise econômica, ora agravada pela crise sanitária que eclodiu no mundo no início de 2020. Fora identificado a impossibilidade de gerir a nova situação, utilizando-se dos mesmos moldes do período chamado de "normalidade" em se tratando de relações de trabalho, que ainda que desprovido de constitucionalidade, com a crise pandêmica, tornou-se ainda maior tal incompatibilidade. 
No mesmo período pandêmico, também se revelou uma fragilidade por parte dos trabalhadores, que embora sempre tenha existido, constatou-se um maior aprofundamento, considerando-se principalmente o declínio da produção econômica mundial. Gerando fortes ondas de desemprego, ainda que compondo um meio heterogêneo, com diferenciações existentes de acordo com a localização geográfica, necessitou contar urgentemente com uma maior intervenção do Estado nacional no mercado econômico, constituindo uma realidade que vinha de uma liberdade econômica com uma crescente intervenção pública na economia.

No intuito de sobrevivência em razão da desaceleração global, foi necessário criar alternativas individualizadas e aos Estados sobreveio a necessidade de intervenção na ordem econômica, no sentido de manter supridas as necessidades básicas da população, no intuito de promover um reinício das atividades econômicas.

A partir da presente pesquisa, objetiva-se demonstrar a necessidade de regulamentação das novas formas de prestação de serviços, em especial, o trabalho prestado por meio de plataformas digitais, cujo processo de precarização aprofundou-se no período pandêmico, levando em conta o valor social do trabalho, principalmente por se constituir como um dos fundamentos da República (artigo $1^{\circ}$ IV da C.F.), a fim de que sejam solucionados entraves sociais e conjunturais da atualidade, e que simultaneamente, não venham comprometer gerações futuras.

Em vista disso, por meio da pesquisa bibliográfica, abordará os conceitos de valor do trabalho. Na sequência, serão tratados os problemas relacionados à formação da gig economy e o impacto dos meios tecnológicos no meio ambiente do trabalho, e discute a formação da relação de emprego em ambiente tecnológico de execução de trabalho.

Ao fim, para consecução dos objetivos delineados neste estudo, adotou-se o método empírico-dialético e as ferramentas de Law and Economics, que por meio de dados secundários, compõem a última seção do presente estudo com a verificação da performance ocupacional no curso da atual crise sanitária.

\section{2 - O VALOR DO TRABALHO E AS NOVAS TECNOLOGIAS}

Segundo Amorim (2010, p.192), a categoria trabalho possui várias vertentes de análise as quais permitem estabelecer "duas modalidades de estudos: um histórico e outro puramente teórico". O primeiro está relacionado ao desenvolvimento socioeconômico e ao surgimento do capitalismo. E o segundo, "refere a substituição paulatina da racionalidade econômica para uma racionalidade voltada para o bem-estar social”. 
Adita ao eixo teórico, a "teoria dos novos movimentos sociais" (ALONSO, 2009, 46-86), amparada numa diversidade de processos sociais que cogitam análises mais amplas, e não exclusivamente o trabalho, e a teoria da sociedade pós-industrial, como uma sociedade na qual predominam valores pós-materialistas, distintos daqueles das conjunturas precedentes baseados na economia e na indústria, e baseada sobretudo, no setor de serviços (BELL, 1977, p. 299).

Segundo este autor, a sociedade pós-industrial é composta por três eixos: social, cultural e político. O pivô é a tecnologia, a qual está baseada no valor-conhecimento em oposição com o valor-trabalho até então conhecido pela sociedade industrial. O valorconhecimento se torna relevante quanto a sua frequência e importância, em desfavor do cumprimento de tarefas da sociedade industrial.

A teoria valor-trabalho, parte da noção de que o valor econômico das mercadorias é avaliado e determinado pelo quantitativo do trabalho empreendido, somados ao trabalho que lhe antecede, tais como na produção de matérias-primas, maquinários, etc. Logo, segundo Marx (2004, p.46):

\begin{abstract}
se considerarmos as mercadorias como valores, consideramos nulas exclusivamente sobre o único aspecto do trabalho social realizado, fixado ou, se se quiser, cristalizado. sob esse aspecto, devemos diferir apenas por representar em quantidades maiores ou menores de trabalho, como, por exemplo, por poder ser empregado num lenço de seda um maior montante de trabalho do que num tijolo. mas como é que se mede em quantidade de trabalho? Pelo tempo que eu trabalho dura medindo o trabalho a hora, ao dia, etc. claro que para aplicar essa medida todas as espécies de trabalho são reduzidas ao trabalho médio ou simples como sua unidade. Chegamos, portanto, a sua conclusão. Uma mercadoria tem um valor porque é uma cristalização do trabalho social. A grandeza de seu valor, do seu valor relativo, depende do maior ou menor montante dessa substância social contida nela, isto é, da massa relativa de trabalho necessário para a sua produção. Os valores relativos das mercadorias são, portanto, determinados pelas quantidades ou montantes respectivos de trabalho empregado, realizado nelas.
\end{abstract}

A análise de Marx obviamente refere-se a questão puramente econômica do valor, tanto sob o aspecto quantitativo quanto qualitativo. É certo que ocorre um abandono pelo capitalismo, em razão da transformação de bens em mercadoria, razão pela qual Marx, amplia a categoria valor diferenciando a categoria de preço e valor.

Ainda sob os aspectos das teorias econômicas em relação ao valor do trabalho, Malthus (1996), Schumpeter (1961) e Menger (1985), o trabalho caracteriza-se por um serviço, assim sendo, é passível de valoração e de negociação em mercado, assemelhando-se a um bem econômico. 


\section{A GIG ECONOMY NO CURSO DA CRISE SANITÁRIA: AS RELAÇÕES DE TRABALHO NO CONTEXTO DAS PLATAFORMAS DIGITAIS}

Tal discussão espraia a propriedade dos meios de produção nos termos dos princípios da ordem econômica, cuja função do Estado é proporcionar os meios de desenvolvimento das organizações, a fim de que seus cidadãos tenham suas necessidades básicas atendidas. Para tanto, desencadeia a análise da Dignidade da Pessoa Humana.

Trata-se de princípio fundamental que permeia a Constituição Federal de 1988, sendo resultado da concepção de centralidade do homem, a como valor intrínseco da sociedade. Segundo Belaunde (1992, p. 394), afirma que "todos os direitos que a Constituição proclama (e aquele que reconhece ainda que pelo seu preâmbulo), de forma, ou de outra sim, caminha para impossibilitar o desenvolvimento integral da pessoa (o que é exigido) pela dignidade dela mesma".

Para Canotilho (2007, p. 225 apud Sarlet, p. 29), ao comentar a constituição portuguesa, define a dignidade da pessoa humana como princípio antrópico que acolhe a ideia pré-moderna e moderna da dignitas- hominis, ou seja, do indivíduo conformador de si próprio e da vida segundo o seu próprio projeto espiritual (plastes et fictor).

$\mathrm{O}$ artigo $5^{\circ}$, inciso XIII, da Constituição, estabelece a liberdade de trabalho sem diferenciação entre pessoa jurídica ou física. O enquadramento do Direito do Trabalho como parte integrante dos direitos sociais possui suporte nos princípios da igualdade que compõe a ordem social, que possui a função instrumental de alcance de justiça.

Nesta perspectiva, segundo Bulos (2009, p. 421), a valorização do trabalho humano é um produto da ordem social - ubi-societas. A sociedade, ao alijar parte de seus indivíduos da fruição do trabalho, torna-o incompleto em sua dignidade e está articulado aos direitos de cidadania.

A Declaração da Filadélfia instituída pela Organização Internacional do Trabalho (OIT), dispõe como "objetivo de manter o vínculo entre o progresso social e crescimento econômico, a garantia dos princípios e direitos fundamentais do trabalho. Deduz que a participação na riqueza de forma justa e igualitária conduz a geração e desenvolvimento do potencial do ser humano.

Tal perspectiva de análise fortalece a interdependência entre progresso econômico em progresso social mantendo inafastável a necessidade de efetividade da Dignidade da Pessoa Humana. É neste aspecto que a análise econômica do direito deve inferir a rota consequencialista dos meios de produção traçando um liame quanto a opção de desenvolvimento que os proprietários dos meios de produção elegem para auferir seus ganhos. 
A OIT por meio do Relatório WESO 2021: The role of digital labour plataforms in transforming the world of work, aponta que as plataformas digitais foram quintuplicadas nos últimos dez anos, fenômeno que ocorre de forma globalizada, inundando a de forma variada a esfera humana (OIT, 2021, p. 107).

\section{3 - A FORMAÇÃO DA GIG ECONOMY E O IMPACTO DOS MEIOS TECNOLÓGICOS NA EXECUÇÃO DO TRABALHO}

Os avanços tecnológicos se situam como elemento das relações sociais, e como tal, deve ser considerado o aspecto histórico e o cunho social relativo à ordem das necessidades humanas e de desenvolvimento, que possuem aspectos simultaneamente positivos quanto ao conhecimento e negativos quanto a produtividade e a taxa de exploração do trabalho humano.

Segundo Harvey (1992, p.167-169), “o regime de acumulação flexível, materializado na espoliação da força de trabalho", reafirmam a relevância da esfera política em razão das novas estruturações produtivas, de acumulação e de sobreacumulação do excedente de capital.

Neste aspecto, insta relacionar o novo reordenamento da divisão internacional do trabalho que se instaurou a partir da década de 70, aprofundado pelas mudanças econômicas e importantes avanços no campo da tecnologia, passando o capital a se movimentar geograficamente, sem respeitar as fronteiras territoriais e políticas.

Tais mudanças quanto a liberdade de tráfego, veio a fragilizar os países periféricos, de economia mais frágil, instaurando de forma definitiva um processo de desenvolvimento desigual, ancorados nos recursos naturais e no trabalho com menor valor, em razão de suas características econômicas fundamentais.

Nesse passo, a compreensão do surgimento da gig economy perpassa pelo período de crise econômica mundial de 2008, que estimulados pelos governos, a fim de prover as necessidades básicas da parcela desalentada da sociedade, fomentou seu desenvolvimento pela via da não regulamentação.

A gig economy está alicerçada nas plataformas digitais e são caracterizadas como um mercado multilateral. Tal multilateralismo é designado pela combinação da força de trabalho e consumidor final, intermediados e geridos pelas plataformas de trabalho. Pode-se afirmar que se trata de um novo modelo de atravessador, um atravessador digital e que vai além da intermediação do consumo e alcança os meios de produção. 
Causam, dentre outras consequências, a própria despersonalização do trabalhador, por meio do crescimento de um individualismo, a ponto de fazer perder de vistas a presença de um coletivo laboral. É como se os que trabalhassem por meio das plataformas estivessem isolados em toda a sua prestação de serviços.

A habilidade em estender sua utilidade de forma massificada em novos setores econômicos, se revela incrivelmente adaptável, demonstrando no curso da crise sanitária iniciada em 2020, agilidade ímpar em termos de atendimento das demandas por serviços Tornaram-se assim, mais aceitos pela sociedade de maneira geral, no sentido de normalização, tanto quanto invisíveis a situação precária que passou a localizar o trabalhador no contexto social e econômico.

No contexto da gig economia, é possível identificar diferenças em seu conceito: um maior que se refere às plataformas de compartilhamento, tais como Airbnb, Blablacar, Drivy, tanto assim como os mercados online, por exemplo E-Bay, Amazon, Submarino, Mercado Livre, etc. E uma menor que se refere a prestação de serviços diretos (IFood, Rappi, etc.) embora intermediados também pelas plataformas.

Numa análise essencial, segundo Olivia Montels (2017, p.7-10), diferencia dois elementos que definem de forma apropriada esses novos modos de produção: a natureza da tecnologia digital e a capacidade de conexão em massa.

É importante ressaltar que neste contexto, ocorre a substituição da uma relação comercial por uma estrutura de produção e de consumidores por meio da canalização de interações sociais e de mercado.

Por outro lado, e o que ainda não está acontecendo, existe a necessidade de classificação das atividades desenvolvidas, a fim de diferenciar e qualificar as empresas que organizam numerosos trabalhadores, e que atendam totalmente ao fim do trabalho decente insculpido na Constituição de 1988, e tornando-o efetivo.

Sob a ótica do contrato de trabalho, é perceptível que as plataformas são empresas empregadoras, ainda que ficticiamente e falsamente afirmam tratar-se de uma das maneiras de aproximação entre consumidores e fornecedores de serviços.

No entanto, o que se revela é a vulnerabilidade e o desprezo a qualquer forma de proteção social para o suposto "autônomo" que presta os seus serviços, revelando-se talvez como uma das mais intensas formas de precarização do trabalho, dirigido por uma perspectiva econômica baseada somente no lucro. 
Olivia Montel (2017, p.7) afirma que "a economia das plataformas não "equivalia a um avanço radicalmente novo, embora seu modelo continue, combine e multiplique dinâmicas já em atividade na maior parte desde 1990”. A transição do trabalhador estável para um trabalhador independente, em termos de política social se revelou precário e de baixa remuneração, intensificado pelo uso das plataformas.

Perfeitamente adequado para o cotidiano urbano e configurado para o setor terciário, um velho conhecido da ciência econômica como setor de mais baixa remuneração (POCHMANN, 2019, p.8).

Deve-se compreender que a gig economy traça o perfil de seu trabalhador como um "empreendedor cotidiano", partindo da noção de flexibilização do Direito do Trabalho, o que sinaliza para uma escala intersetorial (setores primário, secundário, e terciário).

Tal a força do impacto desses novos "modelos de empregos" que se fazem passar por empreendedorismo, nas relações sociais cria um achatamento ainda maior naquilo que é considerado o mínimo resultante das relações de trabalho, caracterizando-se como algo perverso e desprovido de qualquer finalidade social.

No contexto da crise sanitária iniciada no ano de 2020, ocorreu um impulsionamento da gig economy por meio dos novos modelos de emprego, em razão da dispensa ocorrida em massa, o que possibilitou não só o avanço, mas também o aprimoramento das plataformas e de expansão da oferta de mão-de-obra.

Essa expansão se tornou inexorável por uma simples questão de sobrevivência, e principalmente o trabalho por meio de plataforma passou a ser apresentado como um recurso necessário para se evitar o maior contágio pelo coronavírus na população em isolamento social.

Acrescentando-se a tudo isso, os chamados meios telemáticos de trabalho, que se acumulam, ou que também se perfazem por conta das chamadas plataformas digitais. No entanto, é inegável também afirmar que o não respeito aos direitos sociais mínimos, resguardados constitucionalmente, ganhou maior rapidez no que se refere à sua deterioração.

Huws (2017, p. 14), intitula esta classe trabalhadora que emerge da precarização em razão das novas tecnologias, de cibertariado:

A introdução das tecnologias da informação e da comunicação tem como objetivo não a abolição do trabalho, mas seu barateamento e disciplinamento. Ela altera também a divisão de trabalho de colarinho branco, enquanto torna tarefas manuais obsoletas. Os trabalhadores que realizam novos tipos de trabalho rotininizados de processamento de informações, distribuídos em todo o mundo em cadeias de valor 
dispersas, podem ser considerados uma nova subdivisão da classe trabalhadora "um cibertariado".

No contexto do cibertariado, o trabalhador não é considerado um trabalhador, mas um "empreendedor digital”. A relação de trabalho instantânea se caracteriza pela pactuação precária, desprovida de proteção trabalhista e previdenciária, de forma trilateral - trabalhador, plataforma, e tomador de serviços.

Observa-se um conteúdo prestacional diversificado, de tempo determinado e de transitoriedade, sem que ocorra qualquer fixação na empresa de plataforma, de forma autônoma pelo prestador de serviço. O salário é por tarefa, ainda que esteja presente (log in) na plataforma, vindo a subverter o conceito geral de remuneração pelo "estar à disposição da empresa".

Em uma análise simples, as empresas chamadas de plataformas e os consumidores, obtém vantagens mútuas por essa forma precária de prestação de serviços, como por exemplo, o barateamento na entrega do produto ou prestação de serviços, fazendo como que ambos sejam responsabilizados pelos danos sociais sofridos por aqueles que são os diretos prestadores que vendem a sua força de trabalho para tal resultado.

Como maior característica das relações de trabalho na gig economy está na centralidade informacional, isto é, se trata da gestão pela plataforma por meio da inteligência artificial algorítmica, que são simultaneamente utilizados para contratação, dispensa e controle digital contínuo de processamento aferição, análise, avaliação, com o conhecimento total por parte da plataforma acerca da conduta do trabalhador, que no curso da atividade, quer até mesmo em sua geolocalização.

Tais algoritmos são desconhecidos pelos trabalhadores, que podem ser desconectados a qualquer momentos ou ainda, direcionados a determinadas tarefas que os algoritmos, porventura, tenham identificados. Concluindo-se que as plataformas são destituídas de neutralidade, e são empresas capitalistas com objetivo de lucro.

\section{4 - O CORRETO USO DAS FERRAMENTAS TECNOLÓGICAS NAS RELAÇÕES DE TRABALHO: O CUMPRIMENTO DO VETOR CONSTITUCIONAL}

O fenômeno observável nas empresas que constituem gig economy refere-se à ausência dos limitadores característicos das relações de emprego, em especial no que se refere às proteções à saúde do trabalhador. Ausente a pessoa física do proprietário dos meios de 
produção (patrão), escolha de horário de trabalho, locais de trabalho indetermináveis constituem um novo processo ou forma de flexibilização das relações de trabalho antes não mensurável.

Numa análise rasa, propõe-se a não existência de uma relação de emprego e o trabalhador situa-se na condição de empreendedor que ao mesmo tempo possui somente sua força de trabalho, mantendo-o na posição de hipossuficiente agravado agora com o risco da atividade.

Entretanto, ao examinar de forma mais acurada, constata-se o controle por parte da plataforma sobre o prestador de serviço, encontrando-se praticamente todos os elementos que caracterizam uma relação laboral: subordinação, alteridade, onerosidade, pessoalidade, e não eventualidade, art. $2^{\circ}$ e $3^{\circ}$ da Consolidação das Lei de Trabalho (CLT), adicionando-se a tudo isso a sua situação de hipossuficiência.

Examinando um a um, a subordinação é derivada da relação jurídica de emprego e o estado de dependência de seu empregador. Está claro haver uma dependência do prestador e a plataforma. Se esta, por exemplo, entrar em manutenção, não haverá distribuição de trabalho. A alteridade é decorrente da assunção dos riscos da atividade econômica, também existente em grau elevado.

Quanto a onerosidade, caracteriza-se pela modulação dos preços dos serviços prestados pelas plataformas; quanto a pessoalidade, identifica-se a relação intuito personae e se estabelece na individualização do acesso às plataformas por meio dos smartphones, e finalmente, a não eventualidade, que se caracterizada pela frequência habitual, repetitiva e rotineira.

A Carta Constitucional de 1988, dispõe no caput do artigo 170, que a atividade econômica, isto é, os meios de produção, devem atender a princípios que se fundam na valorização do trabalho humano e na busca do pleno emprego.

Ora, quando o vetor constitucional dispõe sobre emprego, há uma concepção e um objetivo que simultaneamente limita e exclui os fatores de produção econômico, baseados na ausência de proteção social. Logo, não há que se falar na manutenção da desregulamentação do trabalho e das atividades desenvolvidas via plataformas.

Também, agora dentro de um enfoque maior, sob o prisma da valorização do trabalho humano, percebe-se que ainda que se discuta sobre a existência ou não de uma relação de emprego no trabalho prestado por meio das plataformas, resta constitucionalmente a proteção de qualquer tipo de trabalho. Isso significa que talvez a questão não deva se 


\section{A GIG ECONOMY NO CURSO DA CRISE SANITÁRIA: AS RELAÇÕES DE TRABALHO NO CONTEXTO DAS PLATAFORMAS DIGITAIS}

circunscrever à existência ou não de uma relação de emprego e sim no fato que a proteção ao trabalho pressupõe a proteção de qualquer forma de trabalho e não somente aquela tipificada como relação de emprego.

Dentro dessa análise, puramente constitucional, pode-se afirmar que independentemente da existência ou não de uma relação de emprego, o trabalho prestado ou intermediado por empresas, que se dizem se tratar de plataformas, não é desprovido de proteção social, a ponto de até poder ser afirmado que, tanto a empresa intitulada como plataforma e os próprios consumidores ou beneficiados pelos trabalhos prestados, ambos são responsáveis, dentro da cadeia produtiva, pela não geração de resultados sociais.

\section{A ANÁliSE ECONÔMICA DO DIREITO (AED) NA ESFERA DO DIREITO DO TRABALHO: UMA CONJECTURA PRELIMINAR}

Segundo Salama (2008, p.11), cita-se aqui a Escola de Chicago e a Escola de Yale, a primeira apresenta uma visão estritamente matemática do Direito, considerando a eficiência como impositivo ético para um ordenamento jurídico. E a segunda, se debruça sobre o custo das transações que envolvem as indenizações entre particulares, objetivando a minimização dos custos acidentários. Nesta ordem, segundo Salama (2008, p. 113 apud Rodriguez):

\footnotetext{
A AED é pautada pela eficiência, equidade e justiça, visando definir a justificativa econômica da ação pública, além de analisar de modo realista as instituições jurídicas e burocráticas e definir papéis úteis para os tribunais dentro dos sistemas modernos de formulação de políticas sociais".
}

Tal raciocínio propõe novos modelos de análise que articulem legislação e seus resultados no meio social. O Professor Gico Jr. ( 2019, p.11) leciona:

\footnotetext{
Enfim, precisamos não apenas de justificativas teóricas para aferição da adequação abstrata entre meios e fins, mas também teorias superiores à mera intuição que nos auxiliem em juízos de prognóstico e diagnose. Precisamos de teorias que permitam, em algum grau, a avaliação mais acurada das prováveis consequências de uma decisão ou política pública dentro do contexto legal, político, social, econômico e institucional em que será implementada. Em suma de uma teoria sobre o comportamento humano.

É neste contexto que começa a ser discutida e considerada no Brasil a Análise Econômica do Direito, cujo propósito é precisamente introduzir metodologia que contribua significativamente para compreensão dos fenômenos sociais e que auxilie na tomada racional de decisões jurídicas.
} 
A discussão empírica cinge-se na vertente entre eficiência e justiça no campo do Direito do Trabalho, cujo modelo da gig economy se apresenta por meio das plataformas digitais de trabalho no contexto da internet. Inicia-se pela diferenciação entre trabalhadores formais e informais, que por obvio, como o próprio nome expõe, cuidam dos trabalhadores sem relação de emprego.

Ocorre que o capital passa a classificar tais trabalhadores como empreendedores individuais. A legislação segue rapidamente para validá-los como autônomos e desguarnecidos dos benefícios sociais da relação de emprego formal. Na Carta de Conjuntura n. 52 publicada pelo IPEA, referente ao terceiro trimestre de 2021, os dados agregados demonstram claramente a performance de ocupação, desconsiderando vínculo empregatício:

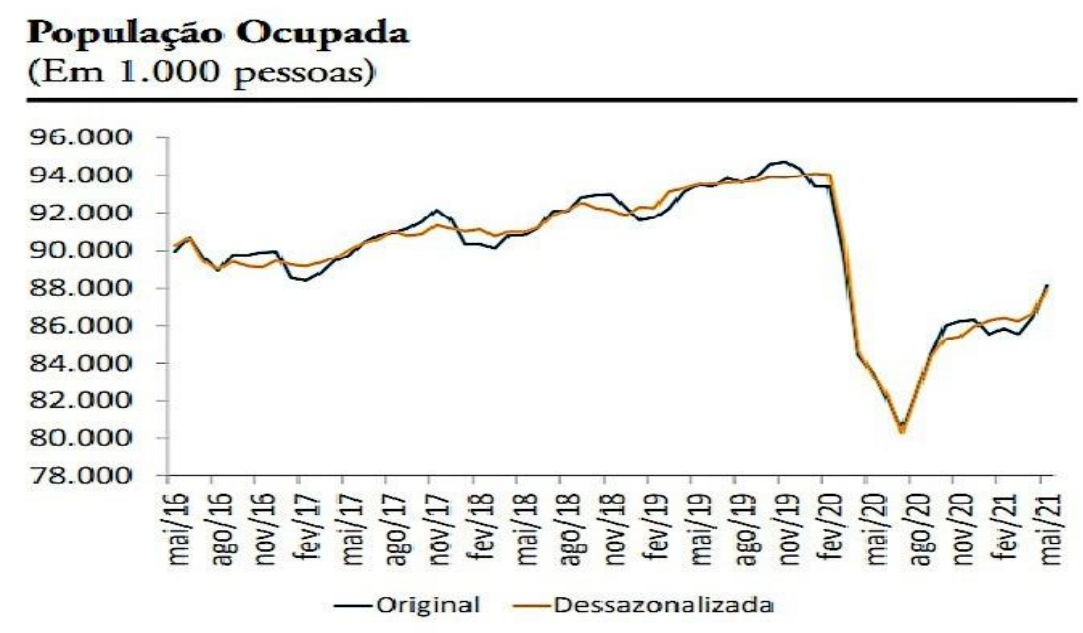

Fonte: IPEA. Carta de Conjuntura n. 52. $3^{\circ}$ trimestre de 2021.

Com a eclosão da crise sanitária, estes trabalhadores informais, segundo a PNAD/IBGE - (Pesquisa Nacional de Amostra de Domicílio Contínua ${ }^{*}$, referente ao ano 2020 apresenta uma queda vertiginosa na taxa de participação na força de trabalho, de 62,1 para 55,1\% da população economicamente ativa (PEA), no segundo trimestre (abril-junho), mantém a queda no terceiro trimestre (julho-setembro), e sofre um leve aquecimento a partir do movimento de vendas para os festejos natalinos, porém permanece abaixo de $57 \%$ do total. Neste ponto o diferencial é quanto a queda drástica num curtíssimo lapso temporal.

Nestes termos, considerando o parâmetro de eficiência, isto é, que se revela de sobrevivência em relação a justiça social, pode-se afirmar utilizando-se apenas desse dado, que a gig economy é ineficiente quanto ao sustento da taxa de ocupação da PEA, e menos 
ainda quanto a promoção da ocupação, vez que não foi capaz de absorver a mão de obra desocupada.

A força de trabalho enquanto componente do processo de divisão social do trabalho, da mesma forma, possui um desempenho similar a ocupação geral ${ }^{\dagger}$ :

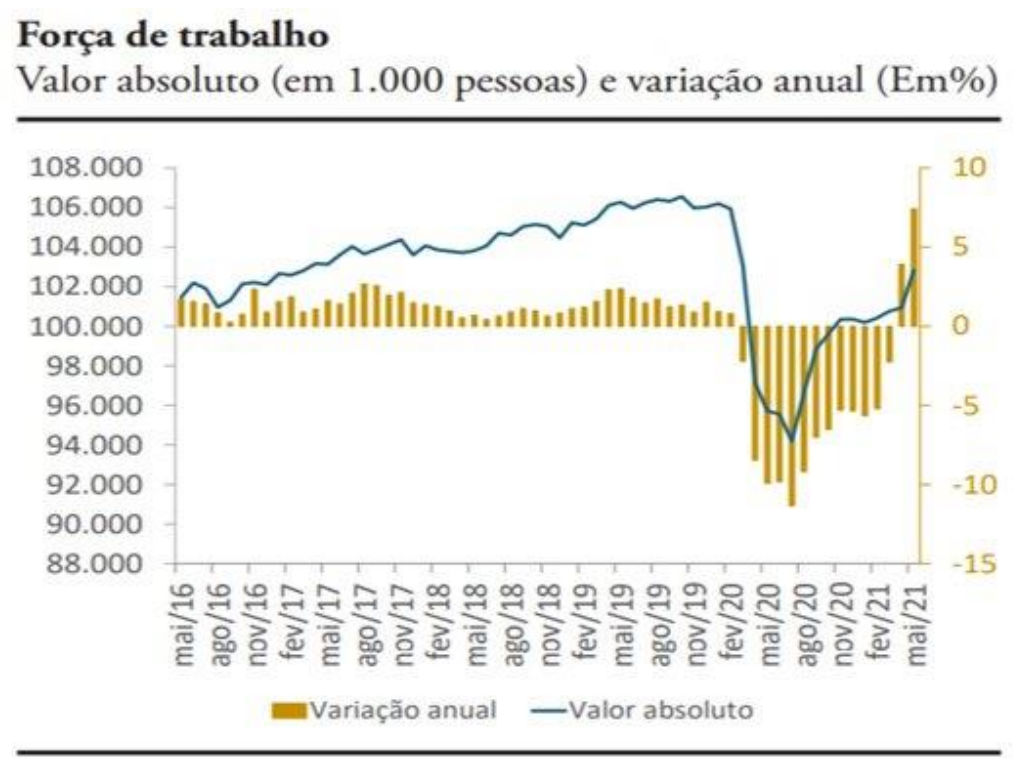

Fonte: IPEA. Carta de Conjuntura n. 52. $3^{\circ}$ trimestre de 2021.

Ultrapassada a questão da eficiência, retorna-se à questão da justiça social onde a gig economy foi desenvolvida e fomentada pela própria desregulamentação do mercado de trabalho que seguia fortemente no contexto socioeconômico pré-crise sanitária.

Ocorre que, como já dito, o setor de serviços é reconhecido como um pagador de baixa remuneração ${ }^{\ddagger}$, em tal formatação passa a ser . Em consequência, a formação da poupança para o sistema de seguridade social será equivalente.

Ao serem mantidas a falta e/ou baixa qualidade de proteção social, característica presente da gig, no caso do Brasil, poderá estar sendo gestado uma massa gigantesca de

\footnotetext{
${ }^{2}$ Segundo Marx, a força de trabalho representa as capacidades físicas e outras a desenvolver pelos indivíduos nos diversos processos de trabalho. MARX, K. Salário, preço e lucro. Elementos para uma teoria da maisvalia. Trad. Edmilson Costa. $1^{\text {a }}$ ed. São Paulo/SP: EDIPRO, 2004.

${ }^{3}$ Para a economia o sentido de força de trabalho está baseado na PEA (população economicamente ativa). IBGE. Instituto Brasileiro de Geografia e Estatística. IBGE Notas Metodológicas -Revisão do projeto de PME. Disponível em : https://www.ibge.gov.br. Acesso em 19/09/2021.

* Segundo Weller (2004, p. 163), existem múltiplas tendências envolvendo a terceirização e por consequência todas as economias possuem processos espúrios e genuínos simultaneamente, variando suas proporções de acordo com o nível de desenvolvimento. WELLER, J. El Empleo Terciario en America Latina: entre a modernidade y la sobrevivência.. Revista de La CEPAL/ONU, v. 84. Santiago de Chile/Chile 2004.
} 
idosos vulneráveis, dependentes do Estado, o que comprometerá as finanças públicas e a sociedade em um curto espaço de tempo.

A União Europeia recomendou a cobertura, ainda que se revele um instrumento frágil, adequações e transparência para alguns tipos de proteção social. Foi recomendado que os trabalhadores independentes devem acessar seguro desemprego, licença maternidade/paternidade, invalidez, acidentes de trabalho, doenças profissionais ou não.

As mesmas proteções também seriam estendidas às outras formas de trabalho que estão sendo criadas, as quais seriam administradas pelo governo e/ou de forma terceirizada.

O artigo terceiro do Tratado da União Europeia objetiva a promoção do Bem-estar para o alcance do desenvolvimento sustentável baseado na alta competitividade e de economia de mercado ${ }^{\S}$, no pleno emprego e no progresso social.

O $\operatorname{artigo} 9^{\circ}$ do Tratado sobre o Funcionamento da União Européia ( TFUE), define as políticas e as atividades e as relacionam à promoção do pleno emprego e estabelece que as mesmas devem estar atender aos objetivos de proteção social, educação de qualidade e proteção da saúde humana.

Este artigo, segundo a Recomendação em tela, apoia e complementa as atividades dos Estados-membros na esfera da seguridade social e da proteção social dos trabalhadores, assegurando as atividades sindicais aos trabalhadores "por conta própria" e/ou empreendedor individual.

A partir de 2017, a União Europeia proclamou o Pilar Europeu dos Direitos Sociais, que estabelece uma proteção social, independentemente do tipo da relação de emprego adotada pelas empresas que atuam em suas fronteiras, e assegurem as garantias adequadas para que todos participem e desfrutem de padrões de vida decente.

No que tange a América Latina e Brasil, a relação mais próxima quanto a implementação de integração regional, o Mercosul é a aliança mais relevante. Em 17 de julho de 2015, a Declaração Sociolaboral do Mercosul veio a reconhecer "que a concretização da

\footnotetext{
$\S$ Segundo Resico (2012, p. 61), [...] Do ponto de vista da organização econômica, existem duas alternativas conceitualmente diferentes: os sistema econômico onde prevalece a iniciativa própria individual ou grupal, denominado sistema de mercado, ou o sistema onde prevalecem as decisões hierárquicas burocráticas, [...] o mercado é a instituição econômica na qual se dá o ponto de encontro entre as duas partes que trocam um bem ou um serviço. A troca é uma forma de aumentar a dotação de bens e serviços à disposição das pessoas, que se distingue de outras formar de fazê-lo, como a apropriação através de fraude, violência e doação altruísta. RESICO, M. Introdução à Economia Social de Mercado. Rio de Janeiro/RJ: Konrad-Adenauer Stiftung, 2012. Disponível em: https://www.kas.de/c/document_library/get_file?uuid=7877ed49-f60f-7d39-6bld5a128f8a1d91\&groupId=265553. Acesso em 23/04/2021.

CONPEDI LAW REVIEW | EVENTO VIRTUAL | v. 7 | n. 2 | p. 119 - 137 | JUL - DEZ | 2021 
justiça social requer indubitavelmente políticas que priorizem o emprego como centro desenvolvimento e do trabalho de qualidade".

Nesta ordem, busca desenvolver o trabalho decente nos mercados de trabalho dos países signatários. São premissas: formular e pôr em prática políticas de trabalho decente e pleno emprego produtivo, articulados com as políticas econômicas e sociais que venha a favorecer geração de ocupação e renda; melhorar as condições de vida dos cidadãos e promoção do desenvolvimento sustentável regional.

No Brasil, desde a edição da Lei n. 13.467/2017, sofreu um retrocesso ímpar. Ao regulamentar o teletrabalho com a introdução no ordenamento jurídico brasileiro dos arts. 75 e 75-E na CLT, refere a intensidade da subordinação. No caso das plataformas digitais, é possível identificar diferentes espécies: teletrabalho subordinado, o teletrabalho autônomo e as plataformas digitais que possui configuração distintas.

É relevante em razão da disparidade econômica entre as regiões brasileiras e algumas delas constituídas por grandes centros hegemônicos e deslocamentos populacionais entre regiões, que impactam diretamente o mercado de trabalho.

A relação direito e economia e economia do trabalho vem se debruçando no estudo das relações socioeconômicas, a fim de explicar os fenômenos sociais. Segundo Pereira (2020, p. 106):

\footnotetext{
Uma série de forças e decisões pode afetar o desempenho em determinadas área, buscando delimitar os fatores que afetam a eficiência do trabalho, sua alocação em diferentes ocupações, setores e segmentos produtivos., bem como os determinantes da correspondente remuneração.

Neste sentido à luz da economia do trabalho se estabelece um novo enlace entre estes dois ramos do conhecimento humano - direito e economia- e busca-se das resposta à demandas de produtividade por parte das empresas e oferecimento de melhores produtos, além da redução dos custos, inclusive dos afetos à mão de obra.
}

As tecnologias vieram a revolucionar modos de produção e relações econômicas e de trabalho como componente fundamental da globalização. É observado a transição de uma sociedade massificada para uma sociedade hiper conectada, inundada por informações e rastreamentos de dados digitais que passaram a ser monetizados.

E são os dados do capitalismo da sociedade digital que oferecem novas diretrizes de novas formas de relação econômica por meio das plataformas.

\section{CONCLUSÃO}


A complexidade do meio ambiente do trabalho, permeado pelas tecnologias disruptivas de exploração do trabalho humano, são o maior desafio do século XXI. Compatibilizar o desenvolvimento humano e desenvolvimento econômico, numa análise rasa, parecem antagônicos, mas na verdade possuem uma relação de dependência mutua.

As atividades econômicas desenvolvidas pelas plataformas iniciou-se timidamente com ciclos de crises econômicas. O Estado de forma astuta, no intento de desvincular o mercado de obrigações constitucionais e infraconstitucionais, e de forma metafórica, assim como o desenho do "Mickey Mágico", impulsionou a mágica do trabalho individual, sem a contrapartida social.

Ocorre que com o passar do tempo, assim como o Mickey Mágico, há uma perda do "controle da mágica", que se reproduz sem parar, criando um contexto socioeconômico perverso do ponto de vista de custo social, vindo a não mais conseguir manter os meios de regulação e controle, não só da cadeia produtiva, mas também da manutenção previdenciária.

Para implementação do chamado desenvolvimento sustentável de forma a produzir seus objetivos de maneira efetiva (Desenvolvimento Sustentável de n. 8 da Agenda 2030, da Organização das Nações Unidas (ONU) - trabalho digno e crescimento econômico), a gig economy deverá cumprir da mesma maneira que outras formas de prestação de trabalho, com a produção de valores sociais.

Logicamente que não existe a possibilidade de recuo tecnológico ou do emprego da tecnologia, considerando o contexto em que as relações econômicas ocorrem, em especial aqui tratando-se sobre a transterritorialidade da economia. Não obstante, tal fundamento não se justifica no que diz respeito a ausência de produção de um trabalho com resultados sociais, constitucionalmente estabelecidos, independentemente de se tratar ou não de uma verdadeira relação de emprego.

A proteção ao trabalho não se circunscreve ao trabalho prestado apenas sob o viés da relação de emprego e sim sobre qualquer forma de trabalho, o que significa a necessidade de se promover, com ou sem regulamentação por força de lei, no respeito aos direitos sociais mínimos, inclusive envolvendo nessa cadeia produtiva a responsabilidade do consumidor de produtos ou serviços oferecidos por tais plataformas.

\section{REFERÊNCIAS DAS FONTES CITADAS}

ALONSO, Ângela. As teorias dos movimentos sociais: um balanço do debate. Revista Lua Nova. 2009, n.76, pp.49-86. Disponível em < https://doi.org/10.1590/S010264452009000100003.>. Acesso em 13.03.2019 às 10:02 hs. 
AMORIM, Henrique. Valor-trabalho e trabalho imaterial na ciências sociais contemporâneas. Caderno CRH, Salvador, v. 23, n. 58, p. 191-202, jan./abr., 2010. Disponível em $<$ https://www.scielo.br/pdf/ccrh/v23n58/v23n58a12.pdf >. Acesso 23.04.2021 às 5:43hs.

BELAUNDE, G. SEGADO, F., VALE, H. Los sistemas constitucionales iberoamericanos. El sistema constitucional espanhol. Madrid/Es: Dickinson, 1992.

BELL, Daniel. O adento da sociedade pós-industrial: uma tentativa de previsão social. 1ed. São Paulo/SP: Cultrix, 1997.

BULOS, U. L. Constituição Federal anotada. 9.ed. ver. e atual. Até a EC n. 57/2008. São Paulo: Saraiva, 2009.

BRASIL. Constituição Federal de 1988. Emenda Constitucional n. 107 de 2020. Disponível em <http://www.planalto.gov.br/ccivil_03/constituicao/constituicao.htm.> Acesso em 25/04/2021 às 9:47 hs.

Consolidação das Leis de Trabalho - CLT. Disponível em :

<https://www2.senado.leg.br/bdsf/bitstream/handle/id/535468/clt_e_normas_correlatas_1ed.p df.> Acesso em 12.03.2021 às 19:53.

Lei n. 13.467 de 13 de julho de 2017. Altera a Consolidação das Leis do Trabalho. Disponível em <http://www.planalto.gov.br/ccivil_03/_ato2015-2018/2017/lei/113467.htm> Acesso em: 16.09.2021 às 15:25 hs.

Declaração Sociolaboral do Mercosul de 2015. Disponível em:

<https://documentos.mercosur.int/simfiles/declaraciones/58033_PT_Declaração\%20Sociolab oral.pdf >. Acesso em 16.09.2021 às 16:30 hs.

EU. European Union. Tratado Sobre o Funcionamento da União Europeia (TFUE).

Disponível em: <https://eur-lex.europa.eu/eli/treaty/tfeu_2012/oj.> Acesso em 17.09.2021 às 7:40 hs.

EU. European Union. Pilar Europeu dos Direitos Sociais. Disponível em:

$<$ https://ec.europa.eu/info/strategy/priorities-2019-2024/economy-works-people/jobs-growthand-investment/european-pillar-social-rights/european-pillar-social-rights-20-principles_pt> Acesso em 16/09/2021 às 14:23 hs.

EU. European Union. Council Recommendation of November 2019 on access to social protection for workers and the self-employed (2019/387). 2019. Disponível em:

$<$ https://eur-lex.europa.eu/legalcontent/EN/TXT/?uri=CELEX\%3A32019H1115\%2801\%29>. Acesso em 10.04.2021 às 6:23 hs.

EU. European Union. COUNCIL OF THE EUROPEAN UNINION. Council Recommendation of November 2019 on access to social protection for workers and the self-employed (2019/387). 2019. Disponível em <https://eur-lex.europa.eu/legal- 
content/EN/TXT/?uri=CELEX\%3A32019H1115\%2801\%29>. Acesso em 10.04.2021. às 20:47hs.

GICO JR. Ivo. Introdução ao Direito e à economia. In: TIMM, Luciano (Org.). Direito e Economia no Brasil: estudos sobre a análise econômica do Direito. Indaiatuba/SP: Ed. Foco, 2019.

HARVEY, David. Condição pós-moderna. Trad. Adail Ubirajara e Maria Stella Gonçalves. 1ed. São Paulo/SP: Loyola, 1998.

HUWS, Ursula. A formação do cibertariado. Trabalho virtual em um mundo real. 1ed. Campinas/SP: Ed. Unicamp, 2017.

IBGE. Instituto de Geografia e Estatística. Sistema de Dados Estatísticos SIDRA.

Disponível em: <https://sidra.ibge.gov.br/home/pnadct/brasil>. Acesso em: 10.04.2021 às 21:45 hs.

IBGE. Instituto Brasileiro de Geografia e Estatística. Pesquisa Nacional de Amostra de Domicílio-Contínua. Disponível em <https://covid19.ibge.gov.br/pnad-covid/trabalho.php> Acesso em: 20/04/2021 às 8:02 hs.

IPEA. Institutos de Pesquisa Econômica Aplicada. Carta de Conjuntura n 52. $3^{\circ}$ Trimestre 2021. Disponível em:

<https://www.ipea.gov.br/cartadeconjuntura/index.php/category/mercado-detrabalho/.>Acesso em 19/09/2021 às 13.15 hs.

MALTHUS, Thomas R. Princípios de economia política e considerações sobre sua aplicação prática; ensaio sobre a população. São Paulo: Nova Cultural, 1996.

MARX, K. O Capital. Crítica da Economia Política. Vol. 1, Livro Primeiro - O processo de Produção do Capital. Tomo1. Col. Os Economistas. São Paulo: Abril Cultural, 1983.

MENGER, Karl. Investigations Into The Method Of The Social Sciences With Special Reference To Economics. E-book. New York: New York University Press. Disponível em: $<$ https://cdn.mises.org/Investigations\%20into\%20the\%20Method\%20of\%20the $\% 20$ Social $\% 2$ 0Sciences_5.pdf.> Acesso em 18.09.2019 às 15:12 hs.

MISES, L. V. Socialism: an Economic and sociological analysis. E-book. New Haven: Yale University Press, 1951. Disponível em:

<https://cdn.mises.org/Socialism\%20An\%20Economic\%20and\%20Sociological\%20Analysis _3.pdf.> Acesso em 30.04.2021 às 7:45 hs.

MONTEL, Olivia. L'économie des plateformes: enjeux pour la croissance, le travail, l'emploi et les politiques publiques. Document d'études. Direction de lãnimation de la recherche, des études et des statiques. n. 213, Août 2017. Disponível em $<$ https://www.epsilon.insee.fr/jspui/bitstream/1/60973/1/DE213.pdf >. Acesso em 31.03.2021 às $8: 57 \mathrm{hs}$ 
OIT. Organização Internacional do Trabalho. Relatório WESO 2021: The role of digital labour platforms in transforming the world of work. Disponível em: <https://www.ilo.org/global/research/global-reports/weso/2021/WCMS_771749/lang-pt/index.htm. > Acesso em: 17.07.2021 às 20.12 hs.

PALAGASHVILI, Liya. Barriers to Portable Benefits Solutions for Gig Economy

Workers. The Center for Growth and Opportunity at Utah University, 2020. Disponível em: $<$ https://www.thecgo.org/research/barriers-to-portable-benefits-solutions-for-gig-economyworkers/\#removing-barriers-toward-greater-portability>. Acesso em: 05.4.2021 às 21:30 hs.

PEREIRA, Daniel Q. Direito e economia das relações individuais de trabalho. In: PINHEIRO, Armando C., PORTO, Antônio M.; SAMPAIO, Patrícia R. P. (Coord.). Direito e Economia do Trabalho. Rio de Janeiro/RJ: FGV Direito Rio Editora, 2021.

POCHMANN, M. Tendências Estruturais do mundo do trabalho no Brasil. Revista Ciência \& Saúde Coletiva, v.25, n.1. Rio de Janeiro, jan. 2020. DOI http://dx.doi.org/10.1590/141381232020251.29562019. Disponível em:

<https://www.scielo.br/scielo.php?script=sci_arttext\&pid=S1413-81232020000100089> Acesso em 10.09.2021 às 13:35 hs.

SALAMA, B. M. O que é pesquisa em direito e economia? In: Cadernos de Direito GV, caderno 22, vol. 5, n. 2. São Paulo, FGV, 2008.

SALAMA, B. M. O que é "direito e economia"? Revista de Direito da Universidade Salvador. Disponível em <https://revistas.unifacs.br/index.php/redu/article/viewFile/2793/2033> Acesso em: 23.03.2021 às $9.47 \mathrm{hs}$.

Sarlet, Ingo W. Dignidade da Pessoa Humana e Direitos Fundamentais. 10 a ed. Porto Alegre: Livraria do Advogado, 2001. 